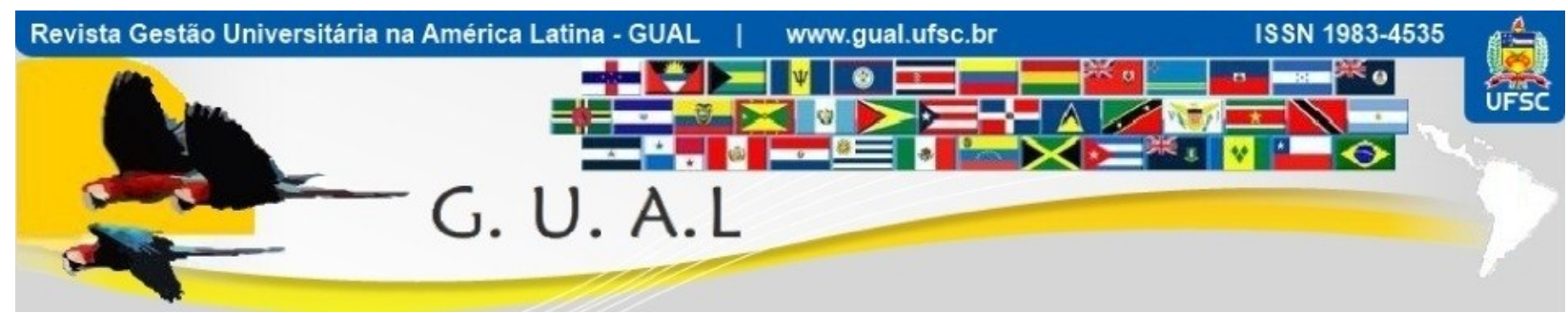

DOI: http://dx.doi.org/10.5007/1983-4535.2012v5n3p67

\title{
DIAGNÓSTICO E ALTERNATIVAS DE CONTENÇÃO DA EVASÃO NO CURSO DE ADMINISTRAÇÃO EM UMA UNIVERSIDADE PÚBLICA NO SUL DO BRASIL
}

\section{DIAGNOSIS AND ALTERNATIVES FOR CONTAINMENT OF DROPPING OUT IN THE ADMINISTRATION COURSE}

Simone Portella Teixeira de Mello, Doutora Universidade Federal Pelotas - UFPel sptmello@gmail.com

Elaine Garcia dos Santos, Especialista Universidade Federal Pelotas - UFPel elainezitzke@gmail.com

Recebido em 06/junho/2012

Aprovado em 22/agosto/2012

Sistema de Avaliação: Double Blind Review

Esta obra está sob uma Licença Creative Commons Atribuição-Uso. 


\title{
RESUMO
}

Este estudo é parte de projeto de pesquisa, desenvolvido em uma universidade pública no sul do Brasil e tem como objetivo revelar os fatores que contribuem para evasão no curso superior de Administração no período de 2009 a 2011. Conforme ampliação das vagas no ensino superior público brasileiro, a evasão também tem aumentado, o que infere um problema a ser tratado com atenção pela gestão da educação superior. O diagnóstico é etapa preliminar às ações futuras para minimizar a evasão das IES. Faz-se revisão teórica sobre o tema, relacionando causas informadas com a literatura. Revelam-se alternativas no âmbito do curso e de políticas institucionais. A pesquisa é de essência qualitativa e utiliza entrevista semi-estruturada com questões abertas e fechadas, desenvolvidas via email e telefone. Os resultados revelam: homens evadem mais que mulheres, a idade predominante está entre $21 \mathrm{e}$ 29 anos. As justificativas predominantes dos evadidos, para a evasão são: carga horária de trabalho excessiva, incompatibilidade de horário entre trabalho e curso e expectativas diferentes com relação ao curso. Controle on line da freqüência do aluno, melhor relação aluno-curso-docente, bolsas de permanência e ações prospectivas como divulgar o perfil do egresso-administrador no ensino médio, podem conter a evasão.

Palavras-chave: Evasão no ensino superior. Abandono na educação superior. Evasão.

\begin{abstract}
This study is part of a research project developed in a public university in southern Brazil. It aims to reveal factors that contribute to dropout in Administration Course from 2009 to 2011. As the places in Brazilian public higher education are amplified drop out has also increased, which implies a problem to be handled carefully by the management of higher education. The diagnosis is a preliminary step for future actions to minimize dropout in Higher Education Institutions. It is a theoretical review on the subject relating causes reported on literature. Alternatives are disclosed in the course and in institutional policies. The research is qualitative and uses semi-structured interview with open and closed questions carried out by e-mail and telephone. The results reveal: dropout rates are higher for males than for females, the predominant age is between 21 and 29 years old. The main reasons for dropout are: excessive workload, incompatibility between work time and the course, and different expectations about the course. Online control of the students' attendance, better studentcourse-professor relationship, Permanence Scholarship, and prospective actions as publicizing in High Schools the profile of the graduate Administrator may restrict the dropout.
\end{abstract}

Keywords: Dropout in higher education. Leaving higher education. Dropout. 


\section{DIAGNÓSTICO E ALTERNATIVAS DE CONTENÇÃO DA EVASÃO NO CURSO DE ADMINISTRAÇÃO EM UMA UNIVERSIDADE PÚBLICA NO SUL DO BRASIL DOI: http://dx.doi.org/10.5007/1983-4535.2012v5n3p67}

\section{INTRODUÇÃO}

Ao mesmo tempo em que o Brasil vive uma expansão significativa em se tratando de oferta de vagas no ensino superior público, problemas atuais vinculados ao abandono do curso tem sido mais alarmantes, o que implica novas articulações da gestão universitária para além das políticas de acesso, de modo a ratificar o compromisso social da universidade e de contribuir para o desenvolvimento necessário em se tratando de melhores índices na educação superior.

Observa-se, a partir da literatura sobre o tema, que os estudantes não abandonam os cursos superiores por grandes e únicas razões, mas por um acúmulo de vários motivos. Ou seja, não aparece um grande motivo, mas uma sucessão de pequenos. É o que salienta Corts, ex-presidente da Samford University, citado por Silva Filho et al (2007) ao enfatizar a diversidade e complexidade das pesquisas sobre evasão.

O tema tem sido debatido e ações têm avançado no sentido de conter índices preocupantes, por meio de bolsas de permanência na universidade, que subsidiam moradia, alimentação, transporte, entre outras demandas. Mas, observa-se que a situação não se limita à condições sócio-econômicos dos estudantes. Falta de informação sobre os cursos, a dificuldade de acompanhar as aulas por ter realizado um ensino médio precário, muitas vezes em etapas, assim como a desistência e o abandono do curso diante da didática docente e das tensões na relação aluno-professor aparecem como justificativas para o abandono do curso.

Ao que tudo indica, a evasão nas IES brasileiras ultrapassam o índice de 20\%. Em 2009, por exemplo, a evasão foi de 20,9\%, segundo Censo do MEC. Apenas 47,2\% dos estudantes se titularam após quatro anos de curso. As perdas financeiras com a evasão no ensino superior em 2009 chegaram a cerca de R\$ 9 bilhões. (SILVA FILHO et al, 2007). Cursos que exigem mais cálculos, estatísticas e melhor conhecimento nos componentes curriculares da área de ciências exatas também aparecem como vilões na relação evasão versus cursos superiores. A incompatibilidade de conciliar horários entre aulas e trabalho também indica a relação evasão com o turno do curso ofertado. A decepção com o curso oferecido também leva à evasão, já que ele acaba ficando muito distante daquilo que o aluno imaginava fazer antes de entrar na universidade pública.

No Brasil, em 2007 foi instituído o Programa de Apoio a Planos de Reestruturação e Expansão das Universidades Federais (REUNI), através do Decreto n ${ }^{\circ}$ 6.096, de 24 de abril, com o objetivo de criar condições para a ampliação do acesso e da permanência na educação 


\section{DIAGNÓSTICO E ALTERNATIVAS DE CONTENÇÃO DA EVASÃO NO CURSO DE ADMINISTRAÇÃO EM UMA UNIVERSIDADE PÚBLICA NO SUL DO BRASIL DOI: http://dx.doi.org/10.5007/1983-4535.2012v5n3p67}

superior, no nível de graduação, pelo melhor aproveitamento da estrutura física e de recursos humanos existentes nas universidades federais. (MEC, 2007) Diante disso, o estudo sobre o tema revela-se oportuno e urgente, de modo que seja possível conhecer os reais motivos na evasão a partir de um estudo de caso específico como é o Curso Superior de Administração de uma universidade pública federal no sul do Brasil.

\subsection{A EVASÃO}

Evasão significa fuga, desistência, abandono. As definições desse termo variam de acordo com cada instituição. De acordo com o Ministério da Educação - MEC, evasão é a "saída definitiva do curso de origem sem conclusão, ou a diferença entre ingressantes e concluintes, após uma geração completa" (BRASIL / MEC, 1997, p. 19). Ainda de acordo com o MEC, para estabelecer parâmetros metodológicos de forma a garantir a exatidão e comparabilidade dos resultados, evasão fica caracterizada da seguinte forma: Evasão de curso - quando o estudante desliga-se do curso superior em situações diversas tais como: abandono (deixa de matricular-se), desistência (oficial), transferência ou reopção (mudança de curso), trancamento, exclusão por norma institucional; Evasão da instituição - quando o estudante desliga-se da instituição na qual está matriculado; Evasão do sistema - quando o estudante abandona de forma definitiva ou temporária o ensino superior.

Para Ribeiro (2005, p. 56), a evasão é o "desligamento do curso superior em função de abandono (não-matrícula), transferência ou reescolha, trancamento e/ou exclusão por norma institucional; evasão da instituição na qual está matriculado; evasão do sistema: abandono definitivo ou temporário do ensino superior." Mas, para fins deste estudo, adotou-se o conceito do Departamento de Registros Acadêmicos da IES pesquisada, onde evadido é aquele aluno que não solicitou matricula em disciplinas por dois semestres consecutivos, que fica sujeito a que o Colegiado de seu Curso relacione seu nome em documento assinado e encaminhado ao DRA, para que seja considerado em "Abandono". Existem ainda alunos que solicitam o cancelamento de matrícula junto ao DRA por meio de declaração.

\subsection{CAUSAS DA EVASÃO NO BRASIL}

Segundo Silva Filho et al (2007) a taxa anual média de evasão no ensino superior brasileiro, entre 2001 e 2005 foi de $22 \%$, mostrando tendência de crescimento, sendo que ela 


\section{DIAGNÓSTICO E ALTERNATIVAS DE CONTENÇÃO DA EVASÃO NO CURSO DE ADMINISTRAÇÃO EM UMA UNIVERSIDADE PÚBLICA NO SUL DO BRASIL DOI: http://dx.doi.org/10.5007/1983-4535.2012v5n3p67}

é maior nas instituições privadas. Porém, de acordo com o censo do MEC no ano de 2009 o índice teve uma taxa de $20,9 \%$.

Entre as regiões do país, no período de 2001 a 2005, a evasão é menos expressiva na região Norte, mas as demais regiões demonstram taxas quase iguais a nacional. Conforme Silva Filho et al (2007) os estados que possuem maior evasão são os estados do Rio de Janeiro, seguido do Distrito Federal, Rio Grande do Sul, Amapá e Rondônia. E entre os cursos, que apresentaram maiores taxas de evasão nos anos analisados, ou seja, 2009 e 2011 estão os cursos de Processamento de Informação, Marketing e Publicidade, Ciências da Computação, Educação Física, Administração e Matemática, superando a evasão média do Brasil.

Existem diversas justificativas do fenômeno no ensino superior brasileiro. Para Schargel e Smink (2002), há cinco categorias de causas da evasão: as psicológicas, as sociológicas, as organizacionais, as interacionais e as econômicas. As causas psicológicas são resultantes das condições individuais como imaturidade, rebeldia, entre outras. Já nas sociológicas interpretam que o referido fenômeno não pode ser encarado como um fato isolado. As causas organizacionais, por sua vez, procuram identificar os efeitos dos aspectos das instituições sobre a taxa de evasão e as causas interacionais analisam a conduta do aluno em relação aos fatores interacionais e pessoais. No que se referem às causas econômicas, os autores consideram os custos e benefícios ligados à decisão, que depende de fatores individuais e institucionais, uma categoria expressiva no que tange à evasão.

Gaioso (2006), ao entrevistar dirigentes e estudantes apontou as seguintes causas para a evasão: falta de orientação vocacional e desconhecimento da metodologia do curso; deficiência da educação básica; busca de herança profissional e imaturidade; mudança de endereço; problemas financeiros; horário de trabalho incompatível com o de estudo; concorrência entre as IES privadas; reprovações sucessivas; falta de perspectiva de trabalho; ausência de laços afetivos com a universidade; falta de referencial na família; entrar na faculdade por imposição; e casamento não planejados/nascimento de filhos. Os dados obtidos por essa autora apontam que a observação do problema por parte das IES é diminuída ou camuflada como algo sem importância, inexistente ou como algo que preferem não falar.

Os trabalhos de Platt Neto et al (2008), consideram motivos que estão fora do controle institucional como a falta de vocação do estudante para a área profissional; a necessidade de o estudante auxiliar sua família, com trabalho e renda; a dependência, por 


\section{DIAGNÓSTICO E ALTERNATIVAS DE CONTENÇÃO DA EVASÃO NO CURSO DE ADMINISTRAÇÃO EM UMA UNIVERSIDADE PÚBLICA NO SUL DO BRASIL DOI: http://dx.doi.org/10.5007/1983-4535.2012v5n3p67}

parte do aluno, de atividade econômica ou emprego que exija viagens; a falta de perfil do aluno para se "formar" numa área de atuação profissional; a incapacidade intelectual do aluno; o abando do curso numa instituição para imediato ingresso em outra, ou no mesmo curso de formação ou não e; doença grave e morte.

Moraes et al (2006) ao detectar que o processo educacional pode contribuir para a evasão, dá como exemplo o aluno estar acostumado a um processo bem diferente do adotado na universidade, onde o aprendizado adquirido anteriormente consiste em memorização, o que não contribui para a formação de um espírito investigador, autônomo, pois no ensino superior, o aluno tem que pesquisar para criar seus próprios textos em vez de copiá-los.

Outros fatores são estudados por Paredes citado por Biazus (2004), onde os fatores internos à universidade são aqueles em que o aluno desistiria do curso em função de descontentamento acerca dos métodos didáticos pedagógicos do corpo docente, ou da infraestrutura da universidade. Já os fatores externos à universidade são aqueles vinculados ao aluno, como a dificuldade de adaptação ao ambiente universitário, problemas financeiros, o curso escolhido não era o que o aluno esperava e problemas de ordem pessoal.

\subsection{AÇÕES INSTITUCIONAIS PARA A REDUÇÃO DA EVASÃO}

A Universidade possui um papel relevante na contenção da evasão escolar no ensino superior, pois através da adoção de políticas institucionais ela poderá auxiliar os alunos a concluírem seus estudos. Para Tigrinho (2008) algumas instituições buscam a solução na interdisciplinaridade para que o curso se torne mais atraente e para que a individualidade do aluno seja respeitada. As práticas buscam integrar o estudante na IES, de modo a sentir-se parte efetiva do processo, integrado e, consequentemente, mais comprometido com o curso que está vinculado. Tais IES acreditam que o estudante faz a escolha pela profissão muito precocemente e que é compromisso da universidade ajudá-lo a organizar seus estudos e a não abandonar o curso. Outras instituições consideram o abandono como conseqüência das dificuldades de empregabilidade e da situação financeira das famílias. Nesse sentido, buscam por meio de descontos e de bolsas de estudo, a permanência do aluno no curso.

Para Spinosa (apud MORAES et al, 2006), há políticas voltadas para a permanência dos estudantes nas universidades, como o fortalecimento de medidas que privilegiam o apoio financeiro e psicológico aos alunos carentes ou a modernização de métodos e de currículos. 


\section{DIAGNÓSTICO E ALTERNATIVAS DE CONTENÇÃO DA EVASÃO NO CURSO DE ADMINISTRACÃO EM UMA UNIVERSIDADE PÚBLICA NO SUL DO BRASIL DOI: http://dx.doi.org/10.5007/1983-4535.2012v5n3p67}

\section{METODOLOGIA}

Este estudo caracteriza-se como pesquisa qualitativa conforme Severino (2006), tendo como etapa preliminar a revisão bibliográfica sobre o tema em artigos publicados em periódicos Qualis, que é o conjunto de procedimentos utilizados pela Coordenação de Aperfeiçoamento de Pessoal de Nível Superior - Capes para estratificação da qualidade da produção intelectual dos programas de pós-graduação. Após, elaborou-se questionário, tecendo o perfil educacional de alunos evadidos e suas justificativas de abandono do curso, relacionando os fatores que mais contribuíram para o fenômeno e identificando possíveis soluções para minimizar o problema, dentre outros quesitos. A população de 28 evadidos, ou seja, o total dos alunos que abandonaram o Bacharelado em Administração, dos turnos vespertinos e noturnos, no período de 2009 a 2011. Destes, oito concordaram em participar da entrevista, que se deu via contato telefônico e por email. Buscou-se nas entrevistas respostas ao motivo do abandono, relacionando uma série de justificativas para o fato, assim como se o aluno à época da evasão conversou com coordenador do curso, docente(s) ou alguém sobre sua insatisfação e decisão em desistir da graduação. A partir da criação e pré-teste desse instrumento de coleta de dados composto de questões fechadas e abertas.

O tratamento dos dados foi etapa posterior por meio de análise de conteúdo com base em Vergara (2006), destacando variáveis numa perspectiva dedutiva, tendo em vista a relação dos fatos da evasão com a trajetória escolar desses entrevistados, assim como os motivos do abandono e os sujeitos envolvidos ou não nesse problema que a cada dia parecer ser mais expressivo nos cursos superiores no país. A complexidade do tema deste estudo de caso (YIN, 2010), se traduz nas evidências dos elementos que sinalizam para a necessidade dos gestores criarem um diferencial de sucesso no ingresso e permanência no ensino superior. O que é tratado posteriormente.

\section{RESULTADOS E DISCUSSÕES}

Os resultados revelam que dos vinte e oito alunos do Curso de Administração, no período de 2009 a 2011, que foram identificados nos registros acadêmicos da IES na situação "evasão", oito concordaram em participar da pesquisa. Do total, $75 \%$ são homens e $25 \%$ são mulheres. O intervalo de maior freqüência concentra-se entre 21 a 29 anos de idade, o que compreende $62,5 \%$ dos respondentes. Os demais, $37,5 \%$, variam de 30 a 51 anos, mas destes, apenas um tem a maior idade do intervalo, ou seja 51 anos. Quando questionados sobre onde 


\section{DIAGNÓSTICO E ALTERNATIVAS DE CONTENÇÃO DA EVASÃO NO CURSO DE ADMINISTRAÇÃO EM UMA UNIVERSIDADE PÚBLICA NO SUL DO BRASIL DOI: http://dx.doi.org/10.5007/1983-4535.2012v5n3p67}

cursaram o ensino médio, ano de conclusão e se foi em escola pública ou privada, observa-se que o percentual mais expressivo foi o de $37,5 \%$ com ensino médio concluído em 1999, sendo que a metade deste percentual de $37,5 \%$ cursou o ensino médio em escola pública e a outra metade em escolas privadas na cidade e região. Os demais entrevistados informaram seus ingresso entre os anos 2000 a 2002, mas sem freqüência mais expressiva.

As informações também indicam que 37,5\% dos investigados ingressaram nos anos de 2005, 2006 e 2008, e os demais, ou seja, 25\% iniciaram o Curso de Administração em 2009 e 2010 . No que se trata do ano de abandono do curso, os dados mostram que $50 \%$ dos respondentes abandonaram no ano de 2009 e os demais 50\% em 2010. Não houve evasão em 2011. Como esclarece Souza e Silva (2003), no plano estrutural, a explicação para casos de pouca permanência na educação formal é o fator econômico. A origem popular e as limitações de recursos financeiros acabam por restringir o planejamento de estratégias escolares de longo prazo, vislumbrando um cenário futuro. Variáveis centradas na competência cognitiva também têm de ser consideradas, no sentido de qualidade do desempenho, em especial no que concerne às notas alcançadas. Redes sociais, no sentido de relacionamentos, também figuram na opção por evadir ou não. Fazer parte de uma categoria que está no caminho de concluir um curso superior em famílias, por exemplo, que têm pouco histórico de qualificação em nível de graduação pode validar a necessidade ou não da graduação. Por isso, a família passa a ser importante, quando se investiga a evasão. As sanções positivas ou negativas da família, controlam a performance do aluno muitas vezes, reforçam aquilo que é julgado como aceitável, mas também desencorajam aquilo que julgam não ser. Logo, não é de se surpreender que o aluno ao tomar a decisão de evadir, não informa a família. Na maior parte dos casos, a família fica sabendo aos poucos dessa decisão e em inúmeros, acaba por ratificar a sentença do aluno, no caso, o abandono do curso.

Pondera-se que nem sempre o curso superior iniciado era a primeira opção dos estudantes. Ao questionar-se se o curso de Administração foi a primeira opção de ingresso na universidade, 62,5\% responderam que essa graduação sempre foi sua primeira opção para ingressar na universidade. Mas 37,5\% responderam não, onde justificam que sua primeira escolha estava com maior evidência no Curso de Direito e após no Curso de Publicidade. Logo, alguns buscam cursos de maior procura, mas usam cursos com disciplinas equivalentes para entrarem na universidade e após buscarem uma re-opção de curso. Em várias instituições, ao longo do ano são lançados editais informando vagas disponíveis em diversos 


\section{DIAGNÓSTICO E ALTERNATIVAS DE CONTENÇÃO DA EVASÃO NO CURSO DE ADMINISTRAÇÃO EM UMA UNIVERSIDADE PÚBLICA NO SUL DO BRASIL DOI: http://dx.doi.org/10.5007/1983-4535.2012v5n3p67}

cursos de graduação decorrentes de abandono, cancelamentos, transferências ou outras circunstâncias. Também nota-se que mais da metade dos entrevistados tinham certeza do curso que pretendiam concluir. Mas, apontam também que tinham consciência do motivo que os levou a abandonar o curso, ou seja, $100 \%$ foram claros ao salientar que sua decisão não foi fortuita. As decisões ditas como definitivas nem sempre são, por fatores que dependem ou não desses entrevistados. Isso talvez seja fruto da modernidade líquida como esclarece (BAUMAN, 2001). Em estágio mais recente, a 'modernidade líquida' expressa por esse filósofo revela que o mundo é caracterizado pela mutação constante, pela fluidez de estruturas, determinando flexibilidade estrutural, organizacional e relacional.

A partir dos estudos de Platt Netto et al (2008), Moraes e Theóphilo (2011), Falcão e Rosa (2008) dentre outros autores, elaborou-se uma relação de motivos que foi apresentada aos entrevistados, que são os seguintes: troca de trabalho e/ou emprego, aqui situa-se situações de trabalho formal ou não, assim como situações que caracterizam estágio remunerado; mudança no trabalho, como sair de uma filial e ir para outra em outra cidade ou local; transferência ou mudança para outra cidade, excetuando-se o motivo trabalho/emprego; a necessidade de sustentar a família, que se dá por um trabalho informal ou expectativas de novo trabalho; carga horária de trabalho excessiva o que infere atrasos e/ou faltas freqüentes; incompatibilidade de horário entre o trabalho e a universidade, o que infere concomitância de horário das aulas e de trabalho, o que é comum em cursos diurnos; reprovação em disciplina(s) do curso; reprovação mais de uma vez na mesma disciplina do curso, solicitando que informasse qual; prática de ensino adotada pelo professor que o evadido não aprova, informando características da didática desse professor(a); transferência ou mudança para outra cidade/estado/país; dificuldade(s) de aprendizagem de conteúdos em disciplina(s); dificuldade na realização das atividades fora da sala-de-aula; problemas de saúde com o evadido; problemas de saúde com familiar ou pessoa que o evadido cuida ou é responsável; expectativas diferentes com relação ao curso, ou seja, esperava mais do curso; ingresso no mesmo curso em outra IES; ingresso em outro curso na mesma IES; ingresso em outro curso em outra IES; pouca identidade entre o perfil do egresso e o perfil do aluno, na medida em que o evadido não se identifica, não se percebe como futuro administrador(a); exigência demasiada de professor(a) na disciplina e pouco atendimento desse fora da sala de aula; e outro que não os anteriormente relacionados, totalizando 17 motivos. 


\section{DIAGNÓSTICO E ALTERNATIVAS DE CONTENÇÃO DA EVASÃO NO CURSO DE ADMINISTRAÇÃO EM UMA UNIVERSIDADE PÚBLICA NO SUL DO BRASIL DOI: http://dx.doi.org/10.5007/1983-4535.2012v5n3p67}

A partir de então, as respostas mostram que a alternativa de maior freqüência é "carga horária de trabalho excessiva", ou seja, carga horária acima de oito horas diárias, o que dificultou a permanência no curso, com percentual de 50\%. Em segundo lugar, a resposta mais freqüente com percentual de $30 \%$ foi a "incompatibilidade de horário entre o trabalho e a universidade", pois relatam que parte da atividade laboral se dava em horário de funcionamento do curso. Ao buscar esclarecimentos sobre o fato, alguns respondentes explicam que saíam do estágio às 14h30min e que as aulas iniciavam às 14 horas, mas que depois houve alteração de horários na universidade e o turno vespertino passou a iniciar às 13:30h, o que tornou inviável a permanência desses, haja vista que já não dispunham de tempo nem para fazer uma refeição rápida.

Já a terceira opção com mais freqüência, 20\%, foi a de que "esperava mais do curso - expectativas diferentes com relação ao curso". Ao buscar esclarecimentos sobre este quesito, os entrevistados mencionam que imaginavam uma estrutura física mais atual, ou seja, softwares em laboratórios de informática, contendo simuladores em áreas da administração como finanças e planejamento, por exemplo, o que vai além de softwares que contenham uma planilha de cálculo eletrônica. Também presumiam laboratórios de informática com configurações atualizadas nos hardwares e com acesso à internet de banda larga, assim como estabilidade dessas conexões.

Infere-se, ainda, que expectativas maiores do que as vivenciadas no curso superior passam por compromissos institucionais, de forma a promover maior conexão entre a teoria e prática, entre o ensino e o mercado de trabalho, sem que o primeiro se torne refém do segundo. Embora os entrevistados não tenham se manifestado sobre quais atividades práticas seriam essas, deduz-se que a partir do curso e demais instâncias da gestão acadêmica, ações como visitas técnicas, ações da Empresa Junior - Emad, eventos de ensino, pesquisa e extensão, estimulariam os alunos a permanecerem no curso, motivando-os a concluírem a graduação.

Dentre os demais motivos do abandono, pois parte dos respondentes assinalaram mais de uma causa, destaca-se a ocorrência de: troca de trabalho/emprego, mudança no trabalho, necessidade de sustentar a família, prática de ensino adotada pelo professor, transferência ou mudança para outra cidade, dificuldade de aprendizagem em disciplina(s), pouca identidade entre o perfil do egresso e o perfil do aluno, alternativas essas indicadas uma única vez pelos respondentes. 


\section{DIAGNÓSTICO E ALTERNATIVAS DE CONTENÇÃO DA EVASÃO NO CURSO DE ADMINISTRAÇÃO EM UMA UNIVERSIDADE PÚBLICA NO SUL DO BRASIL DOI: http://dx.doi.org/10.5007/1983-4535.2012v5n3p67}

Conclui-se, a partir das contribuições de Souza e Silva (2003) que uma das variáveis para a evasão está no grau de identificação existente entre o agente e a instituição. O mundo da sala de aula para os alunos em geral, embora seja um espaço de acesso a conhecimentos é também um mundo com significado secundário, pouco importante. A relação intensa com uma rede social de colegas e/ou com alguns professores pode identificar uma relação mais profícua entre o espaço universitário e o interesse pela sala de aula.

Por isso, também se buscou saber se os entrevistados conversaram com o Coordenador do Curso sobre sua insatisfação na época e como se dava a relação com os docentes. Dos respondentes, $100 \%$ informaram que não conversaram sobre o assunto com o coordenador do curso de Administração. Após questionou-se se conversaram com algum professor do curso sobre sua intenção de abandono e outra vez, obteve-se a resposta de que $100 \%$ não falaram sobre o assunto com nenhum professor. Mas, $25 \%$ dos respondentes comentaram com algum colega de aula na época sobre a intenção de abandonar o curso, mas alegam que nunca consultaram a família sobre a intenção de desistir do curso de Administração. Assim, parece que as redes sociais não foram significativas para a permanência desse aluno, assim como se infere que na rede social familiar a conclusão de um curso superior não se faz tão claramente.

Por fim, perguntou-se ao entrevistado se estavam estudando quando da entrevista para fins desta pesquisa. Dos respondentes, $62,50 \%$ responderam que não estava cursando nenhum curso superior, e 37,50\% responderam que sim. Destes, observa-se que um entrevistado já estava cursando a graduação em Letras quando ingressou no Curso de Administração e atualmente está concluindo pós-graduação lato sensu na área de letras. Outro entrevistado salienta que concluiu o Curso de Publicidade em outra IES e hoje cursa pósgraduação lato sensu em Administração de Recursos Humanos em instituição privada.

\section{CONCLUSÕES PROVISÓRIAS}

Evidenciou-se que nos três últimos anos 28 alunos foram considerados em situação de abandono, um número que não pode ser subestimado em se tratando de um curso que tem grande demanda no ranking das opções de graduação mais escolhidas na atualidade, como é o caso da Administração. Valorizar o discente como pessoa e como futuro profissional administrador, também é compromisso da universidade diante de um mercado altamente competitivo e exigente. A noção de pertencimento enquanto um processo de atitudes que 


\section{DIAGNÓSTICO E ALTERNATIVAS DE CONTENÇÃO DA EVASÃO NO CURSO DE ADMINISTRAÇÃO EM UMA UNIVERSIDADE PÚBLICA NO SUL DO BRASIL DOI: http://dx.doi.org/10.5007/1983-4535.2012v5n3p67}

fazem com que o aluno se sinta parte do contexto universitário parece ser o desafio para se conter a evasão no ensino superior brasileiro. Assim, sem ter o que tinha, diante da evasão ou de não pertencer mais à universidade na condição de discente, e de não alcançar a desejada conclusão de um curso superior, o aluno na situação de abandono, parece que opta pelo silêncio ao lamentar sua condição. O total de respondentes revela isso.

A sensação de abandono infere sentimentos de perda, de fracasso. E tais sensações, nos remetem a um compromisso maior nos projetos pedagógicos em curso, reações que considerem ações que otimizem o diálogo, a conversa e talvez a permanência desse aluno na universidade. Ações mais vigorosas que promovam atuação psicopedagógica prospectiva e não apenas reativa diante de um pedido de socorro eventual por parte de um aluno ou de um alerta de um professor. Ações mediáticas dessa natureza parecem ser cada vez mais necessárias e urgentes nesse novo cenário estudantil do ensino superior brasileiro.

Os incentivos de permanência no curso também podem acontecer e lograrem êxito a partir de uma política institucional que considere um número significativo de bolsas de permanência, tais como bolsas de pesquisa, bolsas trabalho, bolsas para custear alimentação, moradia e transporte. As bolsas não são a solução, fazem parte dela, assim como acompanhamento psicopedagógico, controle de freqüência como indicador de que algo acontece e deve ser investigado, como também um maior e melhor diálogo entre alunos, coordenação de curso e professores. Embora motivos como "exigência demasiada de professor no componente curricular e atendimento precário fora da sala de aula, assim como prática de ensino adotada pelo professor" tenham sido poucos freqüentes nas respostas, sugere-se investimentos na capacitação docente para conter a evasão. Paulo Freire nos ajuda a compreender que o caminho para conter a evasão no ensino superior se faz caminhando e para tanto há de se considerar o que bem salienta o educador quando destaca que "a educação sozinha não transforma a sociedade, sem ela tampouco a sociedade muda.” (FREIRE, 2011)

\section{REFERÊNCIAS}

BAUMAN, Z. Modernidade Liquida. $1^{\circ}$ ed. Rio de Janeiro: ZAHAR, 2001.

BIAZUS, C. A. Sistema de Fatores que Influenciam o Aluno a Evadir-se dos Cursos de Graduação na UFSM e na UFSC: Um Estudo no Curso de Ciências Contábeis. 2004. fls.203 Tese (Doutorado) - Universidade Federal de Santa Catarina. Florianópolis-SC. Disponível em: http://www.tede.ufsc.br/teses/PEPS4285.pdf. Acesso em: 27/10/2011. 
BRASIL / MEC / SESU. Secretaria de Educação Superior / Ministério da Educação. Comissão Especial de Estudos sobre a Evasão nas Universidades Públicas Brasileiras. Brasília, 1996/1997 Disponível em:

http://www.dominiopublico.gov.br/download/texto/me001613.pdf Acesso em 27/10/2011. In: http://revistaensinosuperior.uol.com.br/textos.asp? codigo $=12621$

FALCÃO, D. F.; ROSA, V. V. Um estudo sobre a motivação dos universitários do curso de administração: Uma contribuição para gestão acadêmica no âmbito público e privado. In: $\mathbf{3 2}^{\circ}$ EnANPAD, Rio de Janeiro-RJ, 2008.

FREIRE, P. Educação e mudança. 34a. Ed. - São Paulo: Paz e Terra, 2011. GAIOSO, N. P. de L. da. O Fenômeno da Evasão Escolar na Educação Superior no Brasil. Unesco, 2006. Disponível em: www.iesalc.unesco.org.ve/programas/Deserción/Informe. Acesso em 26/10/2011.

MEC-Ministério da Educação. Diretrizes Gerais do Programa de Apoio a Planos de Reestruturação e Expansão das Universidades Federais - REUNI. Agosto de 2007. Elaborado pelo Grupo Assessor nomeado pela Portaria n ${ }^{\circ} 552$ SESu/MEC, DE 25 de junho de 2007, em complemento ao art. $1^{\circ}, \S$, do Decreto Presidencial n ${ }^{\circ}$ 6.096/07.

MORAES, J. O. de; THEÓPHILO, C. R.. Evasão no ensino superior: estudo dos fatores causadores da evasão no Curso de Ciências Contábeis da Universidade Estadual de Montes Claros - UNIMONTES. Congresso USP, São Paulo, 2006. Disponível em: http://www.congressousp.fipecafi.org/artigos32006/370.pdf. acesso em 26 de outubro de 2011.

PLATT NETO, O. A. da; CRUZ, F.; PFITSCHER, E. D. Utilização de metas de desempenho ligadas à taxa de evasão escolar nas universidades públicas. Revista de Educação e pesquisa em Contabilidade. Brasília, v.2, art.4, p. 54-74. maio/agosto 2008.

RIBEIRO, M. A. O Projeto Profissional Familiar como Determinante da Evasão Universitária: um estudo preliminar. Revista Brasileira de Orientação Profissional. São Paulo, 2005. Disponível em: http://pepsic.bvspsi.org.br/pdf/rbop/v6n2/v6n2a06.pdf. Acesso em: 27 de outubro de 2011.

SCHARGEL, F. P; SMINK, J. Estratégias para Auxiliar o Problema de Evasão Escolar. Rio de Janeiro: Dunya, 2002.

SEVERINO, A. J. Metodologia do trabalho científico. 23. ed. rev. e atual. Cortez Editora, 2007.

SILVA FILHO, R. L. L. et al. A evasão no ensino superior brasileiro. Caderno de Pesquisa, São Paulo, v. 37, n. 132, dez. 2007. Disponível em http://www.scielo.br/scielo.php?script=sci arttext\&pid=S0100-

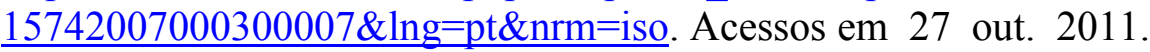

SOUZA, P. N. P. de. Estrutura e Funcionamento do Ensino Superior Brasileiro. São Paulo: Pioneira, 1991, (3-121). 
SOUZA E SILVA, Jaílson de. "Por que uns e não outros?": caminhada de jovens pobres para a Universidade. Rio de Janeiro: Editora 7 Letras, 2003.

VERGARA, S. C. Métodos de coleta de dados no Campo. São Paulo: Atlas, 2009.

TIGRINHO, L. M. V. Evasão Escolar nas Instituições de Ensino Superior. Revista Gestão Universitária. São Paulo, 2008. Disponível em

http://www.gestaouniversitaria.com.br/index.php?option=com content\&view $=$ article\&id $=649$ :evasao-escolar-nas-instituicoes-de-ensino-superior \&catid=135:173\&Itemid=21. Acesso em 27 out. 2011.

YIN, Robert K. Estudo de caso: planejamento e métodos. 4a . Ed. Porto Alegre: Bookman, 2010. 